\title{
A POSSIBILIDADE DE INCORPORAR A PESOUISA NA PRÁTICA COTIDIANA DO PROFESSOR DO ENSINO FUNDAMENTAL
}

\author{
Eliana Maria Oligurski* \\ Graziela Giusti Pachane**
}

RESUMO: O presente artigo objetiva discutir a possível articulação entre ensino e pesquisa na prática pedagógica dos professores dos anos iniciais do ensino fundamental. Baseado na concepção de Demo da pesquisa como princípio educativo e pela compreensão de Freire e Giroux sobre o papel social da escola, o estudo foi realizado em uma escola da Rede Municipal de Campinas-SP, que, por sua localização geográfica e por sua história recente, viu-se impelida a buscar alternativas para aprimorar a aprendizagem dos alunos, para resolver problemas estruturais e conflitos sociais originados pela demanda por vagas para alunos moradores de uma ocupação. Encontrando na pesquisa uma alternativa para seu trabalho, a experiência relatada nos leva a concluir que é possível desenvolver, na escola básica, uma prática pedagógica que articule ensino e pesquisa, tornando esta última fonte catalisadora de desenvolvimento integral e intelectual dos alunos, bem como de integração entre escola e comunidade.

Palavras-chave: Ensino Fundamental; Ensino pela Pesquisa; Ensino e Aprendizagem.

\section{THE POSSIBILITY OF INCORPORATING RESEARCH}

\section{INTO THE ROUTINE PRACTICE OF THE ELEMENTARY SCHOOL TEACHER}

ABSTRACT: This paper aims to discuss the possible link between teaching and research in the teacher's practice in the first years of the Elementary School. The study was based on the conception of research as an educational principle, developed by Demo, on Freire and Giroux' understanding of the social role of the school. The research was conducted in a Municipal Elementary School in the city of Campinas. The geographic localization and the recent history of this school motivated the search for alternatives to improve students' learning, to solve structural problems and social conflicts originated by the claim for vacancies for students living in an occupied area. Taking research as an alternative for their work, the experience reported here lead to conclude that it is possible to develop a pedagogical practice in the Elementary School articulating teaching and research, and taking research as a way to promote the student's intellectual and integral development, as well as the integration between the school and its community.

Keywords: Elementary School; Teaching through Research; Learning and Teaching.

\footnotetext{
* Mestre em Educação pela Pontifícia Universidade Católica de Campinas (PUC-Campinas). E-mail: elianamariamoreno@hotmail.com * * Doutora em Educação pela Universidade Estadual de Campinas (UNICAMP); Professora da Universidade Federal do Triângulo Mineiro (UFTM). E-mail: grazielagp@yahoo.com.br
} 


\section{INTRODUCุÃO}

Já se tornou lugar-comum afirmar que a escola pública "não vai bem” e precisa ser mudada. Sobre essa necessária transformação, entretanto, vale reafirmar que melhorias que se efetuem de modo simplista, alterando apenas suas condições materiais (instalações, equipamentos, material didático, merenda, etc.), propondo reformas curriculares ou o aprimoramento da formação docente, isoladamente, não constituem, de modo algum, o principal passo a ser dado para o alcance da qualidade esperada.

Apesar dos fatores conjunturais-econômicos, defendemos aqui a possibilidade de construção de uma escola de qualidade que assegure a permanência dos alunos e os instrumentalize a compreender e interferir no mundo que os cerca.

Nossa argumentação assenta-se no pressuposto de que a aprendizagem pela pesquisa seria um importante instrumento para a superação da aceitação acrítica da realidade, bem como para a solução de problemas postos, o que poderia resultar em melhores condições de vida para os estudantes e suas comunidades.

Assim, inicialmente, era nosso objetivo discutir a possível articulação entre ensino e pesquisa na prática pedagógica do professor da educação básica, buscando trazer à tona as concepções que professores e alunos têm de pesquisa, analisar os trabalhos que realizam sob essa designação e identificar as condições da escola para o desenvolvimento da pesquisa como princípio educativo, na perspectiva definida por Demo (1997).

No entanto, o que encontramos nas primeiras escolas pesquisadas, a partir do resultado de análise de questionários e entrevistas realizados com professores e alunos, bem como de observações realizadas in loco, apenas confirmavam uma desconfiança: a pesquisa não era utilizada na escola e, quando era, esse trabalho era feito de modo equivocado, em nada se assemelhando ao que buscávamos. Foi comum encontrarmos situações em que a "pesquisa" era incorporada apenas no âmbito do discurso, dizendo tratar-se de escolas que trabalhavam com construção ativa do conhecimento, quando, na verdade, trabalhavam apenas com a elaboração de trabalhos escolares que não incentivavam a criatividade, não fomentavam a criticidade, nem mesmo instigavam a curiosidade dos alunos para a busca de respostas a seus próprios questionamentos. 
A nosso ver, tornava-se imperativa a busca de experiências pedagógicas concretas que superassem uma pedagogia tradicional (pedagogia bancária, nos dizeres de Paulo Freire), caracterizada pela passividade, pela transmissão de conteúdos, pela memorização, pelo verbalismo, etc. e caminhassem no sentido de incorporar a ideia de pesquisa como princípio educativo.

Foi graças ao intermédio de uma colega, docente da Rede Municipal de Ensino de Campinas, que, tomando conhecimento de nossa busca, apresentou-nos a duas professoras responsáveis por conduzir uma experiência que consideramos emblemática do trabalho com a pesquisa como princípio educativo nos anos iniciais da educação básica. Na escola onde lecionam, a partir do contato com dirigentes, professores e alunos, buscamos compreender a experiência ali vivenciada, salientando possíveis conflitos esboçados por mudanças vividas no interior daquele espaço, bem como na região onde se localiza, e o caminho para a conciliação, aproximação, para o entendimento, a partir da "intervenção" das professoras na formação de seus alunos, e seu papel na construção das relações no bairro onde se encontra essa escola, pela via mediadora da pesquisa.

Este trabalho busca, então, resgatar essa experiência e refletir sobre seus resultados, no sentido de contribuir para a discussão teórica e para a efetivação de outras práticas pedagógicas que tenham em seu cerne a pesquisa como princípio educativo. Para tanto, apresentamos, inicialmente, o modo como compreendemos o conceito de pesquisa como princípio educativo, salientando concepções equivocadas de pesquisa que, muitas vezes, são encontradas na escola. A seguir, buscamos demonstrar a relação dessa concepção com a perspectiva histórico-crítica da educação e a importância do papel dos professores como agentes transformadores da realidade. Por fim, apresentamos o relato da experiência que, esperamos, possa contribuir para reflexões a respeito dessa temática, bem como para a realização de outros trabalhos dessa natureza. 


\section{A pesquisa como princípio educativo na escola básica: uma revisão do papel de professores e alunos na interação com o conhecimento}

Costuma-se entender por pesquisa a atividade básica da Ciência na sua indagação e construção da realidade. Para Gil (2002), pode-se definir pesquisa como:

o procedimento racional e sistemático que tem por objetivo proporcionar respostas aos problemas que são propostos quando não se dispõe de informação suficiente para responder aos problemas, ou então quando a informação disponível se encontra em tal estado de desordem que não possa ser adequadamente relacionada ao problema (GIL, 2002, p. 17).

A articulação entre ensino e pesquisa na formação inicial e continuada do professor da educação básica é algo que há algum tempo tem sido abordado na literatura acadêmica (Stenhouse, Elliot, Zeichener, Schön, Lüdke, entre outros), porém pouco ainda tem sido discutido sobre a pesquisa como princípio educativo para este nível de ensino, em especial para os anos iniciais da educação básica. Entre os autores que nos ajudaram a fundamentar nosso estudo, podemos destacar: André (2001), Garcia (2002), Lüdke (2001a; 2001b), Nardi, Bastos e Diniz (2004), Bagno (1998), Demo (1997; 1992,), Giroux (1997), além da edição especial do Caderno de Pesquisas, em seu volume 35 (2005), e de diversos trabalhos de Paulo Freire.

A partir desses estudos, percebemos que, ao tratarmos da introdução da pesquisa no trabalho com os alunos das séries iniciais da escola básica, outra abordagem do termo se faz necessária, diferente daquela apresentada por Gil (2002). Quem nos ajuda a esclarecer essa outra abordagem é Pedro Demo. Para o autor, a pesquisa é vista sob dupla face, complementares, uma como princípio científico e outra como princípio educativo (DEMO, 1992).

No espaço do trabalho na educação básica prepondera a segunda face, porque não está em jogo produzir ciência propriamente, mas construir a metodologia do "aprender a aprender". O autor procura, assim, fundamentar uma proposta de teoria e prática de pesquisa que ultrapasse os muros da academia e da sofisticação instrumental, reforçando a investigação como descoberta, criação e diálogo. Dessa forma, contrapõe-se à ditadura exclusiva do professor-ensina-e-o-aluno-aprende, 
pois esta tende a reduzir os alunos a meros objetos e exalta o professor como autoridade acabada. Sem desfazer dos momentos em que cabe o "aprender", no sentido de internalizar os conhecimentos sistematizados pela humanidade, o autor ressalta ainda que, para a pesquisa como princípio educativo, o contexto deve sempre ser o do "aprender a aprender", base da autonomia emancipatória.

No intuito de melhor compreender esse objeto de pesquisa, Pedro Demo, na primeira parte de sua obra Educar pela pesquisa, aborda a questão da pesquisa tanto na universidade quanto na escola fundamental. Nesta, seu enfoque recai sobre a pesquisa do professor e do aluno. Segundo o autor, a base para a pesquisa tanto do professor quanto do aluno pauta-se por pelo menos quatro pressupostos cruciais: 1) a convicção de que a educação pela pesquisa é a especificidade mais própria da educação escolar e acadêmica; 2) o reconhecimento de que o questionamento reconstrutivo, com qualidade formal e política, é o cerne do processo de pesquisa; 3) a necessidade de fazer da pesquisa atitude cotidiana no professor e no aluno; e 4) a definição de educação como processo de formação da competência histórica e humana (DEMO, 1997, p. 7).

Sob essa ótica, o aluno deixa de ser mero objeto do ensino ministrado pelo professor para se constituir em seu parceiro de trabalho, na busca de solução para os problemas reais por meio de questionamento reconstrutivo.

Nessa abordagem, a pesquisa deve se constituir em atitude cotidiana, tendo como eixo norteador o questionamento reconstrutivo, que implica a construção da competência como atitude da cidadania, a formação do sujeito consciente e organizado, comprometido com a história do seu tempo.

O ensino por meio da pesquisa requer a interpretação, que por sua vez inicia a elaboração própria, pois "Uma coisa é manejar textos, copiá-los, decorá-los, reproduzi-los. Outra é interpretá-los com alguma autonomia, para saber fazê-los e refazê-los. Na primeira condição, o aluno ainda é objeto de ensino. Na segunda, começa a despontar o sujeito com proposta própria" (DEMO, 1997, p. 23).

Ainda de acordo com o autor, dessa forma, essa postura de ensino deveria ser desenvolvida da educação infantil à universidade, pois, pela pesquisa, o professor envolve os alunos pelos passos fundamentais da investigação: a dúvida alimentará a pesquisa de hipóteses alternativas de explicação e de superação de paradigmas. 
A esse respeito, Paulo Freire considera que:

O exercício da curiosidade convoca a imaginação, a intuição, as emoções, a capacidade de conjecturar, de comparar, na busca da perfilização do objeto ou do achado de sua razão de ser. Um ruído, por exemplo, pode provocar minha curiosidade. Observo o espaço onde parece que se está verificando. Aguço o ouvido. Procuro comparar com outro ruído cuja razão de ser já conheço. Investigo melhor o espaço. Admito hipótese várias em torno da possível origem do ruído. Elimino algumas até que chegue a sua explicação (FREIRE, 1999, p. 98).

Também para Marcos Bagno (1998), a pesquisa está presente em diversos momentos do cotidiano. Nesse sentido, o autor aponta para o conceito de pesquisa, começando pela definição da própria palavra:

Pesquisa é uma palavra que nos veio do espanhol. Este por sua vez herdou-a do latim. Havia em latim o verbo perquire, que significava "procurar, buscar com cuidado; procurar por toda parte; informar-se; inquirir; perguntar; indagar bem, aprofundar na busca". Nada a ver, portanto, com trabalhos superficiais, feitos só para "dar nota” (BAGNO, 1998, p. 17).

Tem-se observado que, nos últimos anos, a palavra pesquisa faz parte de inúmeras publicações, planejamentos em educação e em outras áreas. Múltiplas também são as interpretações e os encaminhamentos que a partir dela se desenrolam. Em sala de aula, não haveria de ser diferente: o professor relaciona pesquisar com consultar algumas ou apenas uma obra, recortar de jornais e revistas alguma matéria que se reduz a compor um trabalho que é lido, avaliado e devolvido ao aluno com uma nota ou conceito. Embora esses tipos de atividades sejam movimentos em busca de informação e conhecimento, caminham longe do conceito de pesquisa.

Ainda de acordo com os autores estudados (LÜDKE, 2001; FREIRE, 1999; DEMO, 1997, entre outros), há um erro conceitual que atrapalha na formação de alunos pesquisadores, pois "paira no ar" uma ideia monótona e cansativa de dar conta de uma tarefa com fim em si mesma, sem provocar o aprender a confrontar, comparar, levantar hipóteses, estabelecer relações, transpor conhecimentos para outras situações, outras disciplinas e, mais ainda, não responde às questões: para que e por que pesquisar? Como salienta Marafon (2001): 
Aprender a pesquisar é fazer a suspeita crítica e se lançar na busca de respostas. São estas posturas que devem ser estimuladas e ensinadas na escola. Ao invés de bloquear no aluno sua capacidade de perguntar, é necessário estimular essa capacidade e favorecer os meios para caminhar na descoberta das respostas (MARAFON, 2001, p. 126).

Nessa perspectiva, percebemos que a pesquisa deve ser entendida não como um trabalho maçante ou como uma cópia de trechos de livros e enciclopédias - ou, com o advento do computador, com o uso indiscriminado do "CTRL C + CTRL V" -, mas como atividade básica no processo de apropriação dos conhecimentos escolares, pois, por meio dela, busca-se oferecer o acesso ao conhecimento historicamente acumulado. Por meio da pesquisa, o ensino e aprendizagem podem ser pensados além de um conjunto de conhecimentos sistematizados e apresentados por meio de livros didáticos, que, muitas vezes, desconsideram o contexto escolar dos alunos.

Há de se ter sensibilidade para despertar o interesse do aluno para a pesquisa, fazendo um recorte da realidade plural, contraditória, "caleidoscópica" e optar por um tema que reúna condições para o pensar, o agir com autonomia de pensamento, autoria de criação ou a própria re(construção) do conhecimento acumulado ao longo da história.

É necessário, portanto, desmistificarmos o conceito criado em torno da palavra pesquisa e ressignificá-lo, para reconsiderar essa prática educativa que está muito além do que vem acontecendo. A pesquisa, portanto, está relacionada ao ato de ensinar e aprender; quando os dois acontecem, é porque a pesquisa estava presente, tanto por parte do aluno quanto do professor, já que ambos realizam perguntas, indagações e constatações durante o processo. Isso nos mostra, mais uma vez, que:

Não há ensino sem pesquisa e pesquisa sem ensino. Esses que-fazeres se encontram um no corpo do outro. Enquanto ensino, continuo buscando, reprocurando. Ensino porque busco, porque indaguei, porque indago e me indago. Pesquiso para constatar, contatando intervenho, intervindo educo e me educo. Pesquiso para conhecer o que ainda não conheço e comunicar ou anunciar a novidade (FREIRE, 1999, p. 32).

Assim, é necessário o desenvolvimento de uma concepção de pesquisa que seja utilizada na educação básica como um recurso de ensino e aprendizagem, com o professor construindo, garimpando instru- 
mentos e abrindo frentes, em "sintonia" com os desejos e curiosidades dos alunos. É necessário, ainda, que haja um produto final com fim específico, que garanta a intencionalidade de todo o processo de pesquisa, ou seja, que exista aplicabilidade e que não se encerre nas mãos do professor para receber um conceito apenas.

Nesse sentido, todos, professores e alunos, seremos pesquisadores, desmistificando o conceito de que só algumas mentes privilegiadas, dotadas de habilidades e competências extraordinárias, podem se dedicar à prática investigativa.

Sobre a pesquisa, ainda é possível salientarmos dois aspectos distintos: a pesquisa como caminho para novos conhecimentos - mesmo que sejam novos apenas para o estudante que o (re)constrói - e como possibilidade de resposta a problemas postos.

Entendemos que a pesquisa na escola pode não só preparar o estudante para uma atitude investigativa, de curiosidade, de questionamento, de compreensão, de "processo", mas também, por meio dela, a escola pode inserir-se na sociedade e, pelo trabalho do aluno, auxiliar a resolver problemas da comunidade na qual está inserida.

Essa preocupação está assentada no pressuposto de que a pesquisa seria um importante instrumento referencial para a criação e a superação dos problemas da realidade, o que poderia resultar em melhores condições de vida para a comunidade envolvida.

É igualmente importante lembrarmos que, como atividade humana e social, a pesquisa traz consigo, inevitavelmente, a carga de valores, preferências, interesses e princípios que orientam o pesquisador. Assim, sua visão de mundo, os pontos de partida, os fundamentos para a compreensão e a explicação desse mundo influenciarão a maneira como ele propõe suas pesquisa ou, em outras palavras, os pressupostos que orientam seus pensamentos vão também nortear sua abordagem de pesquisa.

Compreendemos, então, que a pesquisa confere ao professor uma ótima condição para o exercício da atividade criativa e crítica, em que há questionamento, mas também indicação de soluções para os problemas investigados. Dessa forma, a nosso ver, a pesquisa na área educacional alimenta a atividade de ensino e a atualiza frente à realidade do mundo. Embora seja uma prática predominantemente teórica, a pesquisa vincula pensamento e ação. Nessa perspectiva, Minayo (1994) observa que: "nada 
pode ser intelectualmente um problema se não tiver sido, em primeiro lugar, um problema da vida prática". Entendemos, assim, que questões da investigação estão relacionadas a interesses e circunstâncias socialmente condicionadas, são frutos de determinada inserção no real, nele encontrando suas razões e seus objetivos.

Essa concepção de trabalho de pesquisa está associada a uma compreensão de educação voltada para uma pedagogia histórico-crítica, que acreditamos alcançar compreensão maior da função mediadora da escola e do professor no processo de humanização pela via da perspectiva crítica fundamentada em Mello (1982) e Saviani (2000; 2003), ambos apoiados no pensamento de Gramsci, indicando a importância de uma educação voltada aos interesses da classe trabalhadora, em que se supera a visão de instrumento de reprodução, elevando-se a educação a instrumento de luta para as camadas subalternas.

Nesse sentido, a escola deve ocupar o lugar de destaque que merece. Deve ser tratada com generosidade e rigor conceitual, para que construa um projeto aberto para o futuro, vinculado à democracia e em permanente diálogo com as maiorias. Justamente por isso está intimamente associada à proliferação daquele novo tipo de intelectual cujo modo de ser Gramsci dizia não mais consistir na "eloquência", mas numa "inserção ativa na vida prática".

Giroux (1997) defende que uma forma de repensar e reestruturar a natureza da atividade docente é encarar os professores como intelectuais transformadores. Nesse sentido, essa categoria de intelectual é útil de diversas maneiras: primeiro, ela oferece base teórica para a atividade docente; em segundo lugar, esclarece os tipos de condições ideológicas e práticas necessárias para que os professores funcionem como intelectuais; em terceiro lugar, ela ajuda a esclarecer o papel que os professores desempenham na produção e na legitimação de interesses políticos, econômicos e sociais variados, por meio das pedagogias por eles endossadas e utilizadas.

O autor rejeita, assim, a tentativa de redução dos professores a meros técnicos, preparados para executar as ideias pensadas por outros ou simplesmente preocupados com as melhores maneiras de transmitir "dado" corpo de conhecimento. Ao contrário, como intelectuais transformadores, os professores deveriam "exercer ativamente a responsabilidade de propor questões sérias a respeito do que eles próprios ensinam, sobre 
a forma como devem ensiná-lo e sobre os objetivos gerais que perseguem" (GIROUX, 1997, p. 159). Mesmo os estudantes, futuros professores, deveriam, segundo o autor, "aprender a formular questões sobre os princípios subjacentes aos diferentes métodos pedagógicos, às temáticas de investigação e às teorias educativas", em lugar de concentrar-se no como ensinar e que livro usar (GIROUX, 1997, p. 161).

Giroux (1997) acredita que, para que a pedagogia crítica se torne realizável, são precisos dois elementos: entender as escolas como "esferas públicas democráticas", ou seja, "considerar as escolas como locais democráticos dedicados a formas de fortalecer o self e o social", e entender os professores como "intelectuais transformadores":

Com uma linguagem política, as escolas são então defendidas como instituições que fornecem as condições ideológicas e materiais necessários para a educação dos cidadãos na dinâmica da alfabetização crítica e coragem cívica, e estas constituem a base para seu funcionamento como cidadãos ativos em uma sociedade democrática (GIROUX, 1997, p. 28).

Ocorre que, historicamente, o professor da escola básica não tem se compreendido como profissional construtor de saberes a partir de sua prática, mas como um reprodutor/executor do que é apresentado por outrem como melhor ao consumo. O professor fica, então, preso às ideias de um livro didático, a um novo modismo, aos manuais de orientação pedagógica, facilitadores de seu trabalho, situação que, em muitos casos, é reforçada pelas políticas públicas relativas à educação e pelas práticas ocorridas nos cursos de formação de professores.

Julga-se, nesse sentido, a ausência de canais que viabilizem uma relação mais estreita entre quem produz conhecimento e os divulga e os professores, ou, mais ainda, no sentido de possibilitar que o professor seja, ele mesmo, produtor e divulgador de novos conhecimentos.

Supor que o professor é mero executor de propostas teóricas significa, nesses termos, negar a práxis e incapacitá-lo a entender a dimensão da educação como prática de liberdade humana, no sentido atribuído por Freire (1989), de educação para o "homem-sujeito", para um homem que não está no mundo, mas com o mundo (p. 39). O professor executor de teorias-receitas, porque alienado de sua condição pensante, não pode tornar-se educador-sujeito/agente da História/educador-de-sujeitos. A condição que assume, fetichizada pela receita pronta a ser mastigada em 
sua sala de aula, é a do educador-objeto/reprodutor da História/educador-de-homens-objetos.

Nessa perspectiva, ressalta Freire (1989, p. 94-95) que "nada ou quase nada existe em nossa educação que desenvolva no nosso estudante "O gosto da pesquisa, da constatação, da revisão dos achados". Com efeito, a concepção tradicional da educação vê os professores como técnicos de alto nível, ou melhor, apenas transmissores de conteúdos (os especialistas pensam por eles; os executores de planos de ensino, leis e projetos definidos pela burocracia e políticos). Nessa concepção, os problemas de caráter pedagógico-político são reduzidos ao caráter administrativo.

A pedagogia crítica enfatiza a conexão entre valores e fatos, além disso, concebe a escola como local não apenas voltado à instrução, como era na visão de mundo dos tradicionalistas, mas também como local de reflexão, problematização, crítica e autocrítica, local político e cultura. Nos dizeres de Giroux (1997):

Tornar o político mais pedagógico significa utilizar formas de pedagogia que incorporem interesses políticos que tenham natureza emancipadora; isto é, utilizar formas de pedagogia que tratem os estudantes como agentes críticos; tornar o conhecimento problemático; utilizar o diálogo crítico e afirmativo; e argumentar em prol de um mundo qualitativamente melhor para todas as pessoas (GIROUX, 1997, p. 163).

Freire (1980, p. 82), na defesa de uma educação crítica e problematizadora, ressalta as potencialidades de limitação e desafio representadas pelo "aqui e agora" dos homens no mundo; é por isso que o "já-concreto" é tão importante como ponto de partida das reflexões na educação. O diálogo, segundo Freire, "é o encontro no qual a reflexão e a ação, inseparáveis daqueles que dialogam, orientam-se para o mundo que é preciso humanizar" (FREIRE, 1980, p. 83). Por isso, a relação dialógica opõe-se aos métodos bancários que supõem acabamento da realidade e dos homens e mero consumo de ideias de uns pelos outros. A essência dos pressupostos é problematizadora, portanto, afina-se à formação crítica, suscitando "um movimento que compromete os homens como seres conscientes de sua limitação, movimento que é histórico e que tem o seu ponto de partida, o seu sujeito, o seu objetivo" (FREIRE, 1980, p. 82).

Freire (1980) ensina que não se pode dicotomizar diálogo e ação revolucionária: o primeiro é a essência do segundo; não há etapa para um e 
para outro. O método dialógico é, pois, revolucinário, na medida em que intenciona o desvelar da realidade para promover a emancipação humana. " $\mathrm{O}$ método é a forma externa da consciência que se manifesta por atos, que adquire a propriedade fundamental da consciência: sua intencionalidade" (FREIRE, 1980 , p. 86). Também se afirma a necessidade da problematização perante os temas e tarefas que se impõem ao homem em sua época. Diz ele:

[...] saliente-se a necessidade de uma permanente atitude crítica, único modo pelo qual o homem realizará sua vocação natural de integrar-se, superando a atitude de simples ajustamento ou acomodação, aprendendo temas e tarefas de sua época. Esta, por outro lado, se realiza à proporção em que seus temas são captados e suas tarefas resolvidas. E se supera na medida em que temas e tarefas já não correspondem a novos anseios emergentes, que exigem, inclusive, uma visão nova dos velhos temas. [...] sua humanização ou desumanização, sua afirmação como "sujeito" ou sua minimização como "objeto", dependem, em grande parte, de sua captação ou não desses temas (FREIRE, 1980, p. 44).

É necessário considerar que a pesquisa, compreendida como princípio educativo para a educação básica, não busca a construção de conhecimentos "novos" para a ciência, para uma área do conhecimento, mas, sim, conhecimentos novos para aquele estudante que, por meio da atitude investigativa, (re)constrói caminhos de descoberta de conhecimentos que já fazem parte do arcabouço acumulado pelas gerações que o antecederam; ou mesmo busca respostas a indagações dos alunos, a conhecimentos que ainda não foram sistematizados, embora não pertençam diretamente ao campo da ciência.

Assim, quer sejamos professores quer alunos, ao adotarmos uma atitude investigativa perante o conhecimento, possivelmente sofreremos transformações em nossa relação com o processo e com o produto do mesmo. Com Giroux (1997, p. 220), reivindicamos: "A natureza de tal tarefa pode parecer utópica, mas o que está em jogo é valioso demais para ignorar-se tal desafio".

A possibilidade de formar sujeitos críticos, de tornar a aprendizagem mais significativa e mais prazerosa, de resolver problemas cotidianos e de devolver ao professor a autonomia de seu fazer pedagógico são alguns dos aspectos que nos motivaram a buscar práticas no cotidiano de escolas públicas que se pautassem pela perspectiva da pesquisa como princípio educativo, levando-nos à elaboração do presente estudo de caso. 


\section{"De encontro" ou "ao encontro": mais que uma questão gramatical, uma experiência emblemática}

Ao buscar conhecer a possibilidade de incorporar a pesquisa na prática cotidiana dos professores das séries iniciais do ensino fundamental, esbarramos em uma série de dificuldades. A maior era encontrar uma escola onde o trabalho de pesquisa se aproximasse da ideia por nós defendida. Não contentes com a constatação da dificuldade de utilização da pesquisa como princípio educativo na educação básica, instigados por diversos questionamentos e motivados por nossas próprias angústias em relação ao tema, fomos em busca de outras experiências de pesquisa na educação básica.

O caminho foi aberto pelo contato com uma antiga colega de trabalho. Por meio dela, tomamos conhecimento de uma escola municipal da periferia de Campinas que vinha trabalhando, já há algum tempo, com pesquisa na acepção por nós almejada.

Optamos, portanto, pela realização de um estudo de caso. Os dados foram obtidos, inicialmente, por meio de entrevistas com duas professoras dessa escola, realizadas no período de agosto a novembro de 2008. As entrevistas foram realizadas na própria escola, na sala de aula, no quiosque, nos intervalos para café, nos corredores, porém sempre na própria escola.

O material suplementar coletado para essa pesquisa, como fotos, reportagens de jornais, material de alunos, atividades, foram gentilmente cedidos pelas professoras entrevistadas e pelos demais professores da escola, além do material constante do Projeto Político Pedagógico dessa unidade escolar para o biênio 2008/2009.

Ressaltamos que parte dos dados apresentados no Projeto Político Pedagógico 2008/2009 dessa unidade escolar foi fruto dos resultados dos diferentes diagnósticos desenvolvidos pelos professores da escola, nos primeiros meses de aula, e aplicados em todas as turmas, de todos os períodos, com o objetivo de fortalecer as relações da escola com as famílias e articular as atividades escolares ao contexto da realidade local.

A experiência de que trataremos ocorreu com um grupo de seis professoras de terceiras séries dessa escola municipal de ensino fundamental de Campinas, que, nos últimos quinze anos, teve de se adequar a uma nova realidade, em decorrência de diversas ocupações e da formação 
de novos grupos habitacionais nas imediações do bairro onde se encontra. Diante desse quadro, em meados da década de 1990, esse grupo de professoras iniciou uma nova proposta de trabalho, que se foi solidificando ao longo dos anos. E é o resgate da memória desses acontecimentos iniciais que passamos a partilhar, a partir do depoimento de duas das professoras envolvidas nesse movimento, as quais denominamos, a fim de garantir o anonimato, Vanessa e Carol.

A escola onde foi realizada a pesquisa é um estabelecimento municipal voltado à educação fundamental e que, segundo a diretora, está organizada atualmente em três períodos de aula (manhã, tarde e noite), com a consolidação da organização dos ciclos nos anos iniciais do ensino fundamental em Ciclo I, com três primeiros anos (C1.1, C1.2, C1.3), Ciclo II, com dois anos (C2.1, C2.2), das 7 às 11 horas. No caso das séries finais do ensino fundamental, os alunos de $5^{\mathrm{a}}$ a $8^{\mathrm{a}}$ séries são atendidos no horário de 12 às 18 horas e os alunos da Educação de Jovens e Adultos, das 19 às $23 \mathrm{~h}$.

Segundo informações contidas no projeto pedagógico, o bairro onde se situa a escola é antigo, pequeno, de poucas ruas e pouco comércio. As imediações contam com uma grande indústria que, em anos anteriores, colaborava financeiramente com a escola. Há, também em suas proximidades, um complexo penitenciário e dois condomínios residenciais.

Durante as entrevistas, as professoras pesquisadas contaram que essa unidade escolar passou por várias transformações: de escola pequena, que atendia, em dois turnos, somente crianças provenientes do bairro onde está situada, a escola precisou ampliar para três e, posteriormente, quatro períodos, consequência da demanda por vagas das famílias que se apropriaram de terrenos próximos.

Alguns bairros mais antigos no entorno da escola encontravamse estruturados, com rede de esgoto, elétrica, asfalto, água encanada e comércio. Porém, as ocupações mais recentes possuíam pouquíssima infraestrutura e a maioria da população encontrava-se desempregada ou trabalha no mercado informal. A região, de maneira geral, ainda sofria pela falta de melhores condições de moradia, transporte coletivo, creches, áreas de lazer e segurança.

A diversidade socioeconômica e cultural da comunidade escolar refletiu no trabalho pedagógico da escola e exigiu dos profissionais com- 
prometimento político e pedagógico, percepção dos pontos problemáticos nas discussões das contradições existentes, enfim, um trabalho coletivo, que repensasse valores e procedimentos, para que a escola fosse verdadeiramente democrática e competente na sua função, um espaço de transformação.

Assim como a comunidade local passou por transformações profundas, com muitos conflitos entre os antigos moradores e os novos ocupantes da área, a escola também sofreu transformações pedagógicas e estruturais: "Sabíamos que a escola não podia modificar a estrutura social, mas poderíamos trabalhar a partir dos novos ideais comunitários", disse uma das professoras entrevistadas, ainda salientando que, quando pareciam encontrar os caminhos, a estrutura do sistema os forçava a mudarem de escola e o grupo novamente se fragmentava e tudo parecia voltar à "estaca zero".

Até hoje os professores dessa escola buscam conhecer melhor a diversidade das comunidades que vieram de diversas regiões ali se estabelecer, sempre se questionando "para que serve" o tipo de conhecimento que estão construindo e "quais valores são válidos para essa comunidade".

Essa caracterização histórica e geográfica, bem como o compromisso de seus professores e sua compreensão de educação, fez com que a pesquisa se concretizasse como metodologia de aprendizagem, o que é confirmado pela professora Vanessa:

Não é possível entender a opção pela pesquisa sem conhecer a história da escola. Essa nova realidade deu início aos conflitos sociais, exigiu dos profissionais uma nova postura política, novo redirecionamento do trabalho à medida que a realidade se tornava conhecida. Imagina! Uma comunidade bem-estruturada, de classe média baixa, e de repente se viram "invadidos" por uma população que exigia seus direitos.

O corpo docente foi despertado por sentimentos diversos: medo, preconceito, descontentamento, desinteresse em ouvir e trabalhar com o novo, provocando um incômodo geral. Essa escola viveu, a partir daí, períodos de turbulência, choque entre "antigos" e "novos" moradores, choque entre as diferentes "linhas" dos professores e a direção, diferentes olhares sobre a nova clientela, a prática pedagógica e a avaliação.

A professora salientou que os alunos que entravam na escola, vindos das ocupações, não tinham materiais escolares, chegavam à escola sem condi- 
ções de higiene porque não tinham moradia digna, as famílias não se aceitavam umas às outras e os alunos brigavam muito porque as crianças do bairro não aceitavam as crianças da "invasão", o que é confirmado por Vanessa:

Nós tínhamos um problema e tínhamos que resolver. Tinha que se fazer alguma coisa, era um desafio para nós também. O desafio foi e continua sendo enorme, pois, até hoje, os profissionais continuam se empenhando para conhecer e compreender cada vez mais a diversidade apresentada por essa comunidade.

"Os alunos tinham uma defasagem de conteúdos muito grande, mas tinham um conhecimento de seus direitos muito grande também", afirma a professora. Emocionada, lembrou da matéria que saíra no jornal Diário do Povo, da cidade de Campinas, sobre a manifestação dos pais dos alunos por falta de salas de aula para os filhos, e ressaltou: "Se era saudável os alunos assistirem às aulas debaixo das árvores [como havia sido afirmado pelo então secretário municipal de educação], decidimos que 'todos' os alunos da escola assistiriam as aulas ao ar livre”.

\section{FIGURA 1 - Pais e alunos assistem aulas juntos ao ar livre}

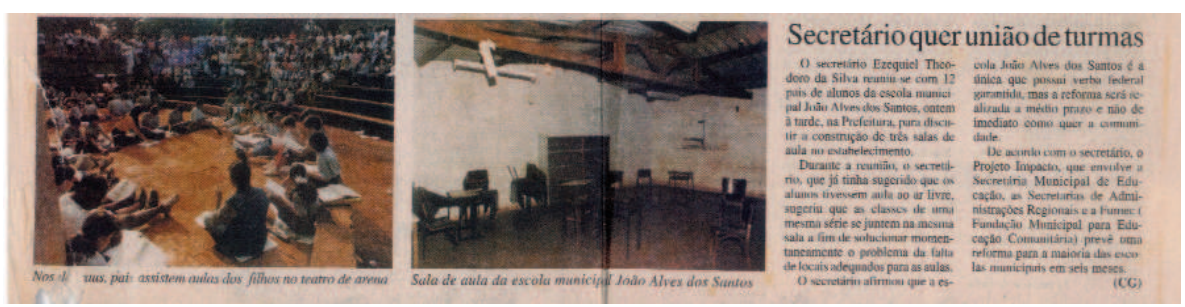

Fonte: Diário do Povo - 12 de abril de 1995.

Assim, a escola permitiu que "os antigos" e "os novos" não entrassem em conflito, que em vez de irem uns de encontro aos outros, ambos fossem ao encontro de novas possibilidades de convivência e crescimento. Estava posta uma necessidade à escola e as professoras tinham de responder a ela. Os caminhos possíveis eram muitos, porém dependiam do compromisso político e pedagógico dos envolvidos. Assim, com base naquilo em que acreditavam, as professoras e os dirigentes da escola fizeram suas escolhas.

Em primeiro lugar, era necessário que aquelas crianças conhecessem quem eram, resgatassem sua identidade, se reconhecessem no contato com o outro. 
O trabalho desenvolvido pelas professoras foi, portanto, iniciado com o resgate da identidade desses alunos. Precisavam criar um clima para falar do outro, para conhecer sua origem, posteriormente, conhecer melhor a cidade e ainda propiciar ao aluno "descobrir" seu papel como cidadão nesse novo horizonte a ele apresentado.

Uma das formas encontradas pelas professoras foi mostrar a valorização do "eu" por meio da confecção do "Livro Identidade", que, ao final da sua confecção, seria mostrado aos pais, para que pudessem conhecer melhor as demais crianças e interagir com o trabalho desenvolvido.

Para recuperar a história de cada aluno, muitos vindos da Bahia ou do Paraná, as atividades iniciaram-se com o desenho do autorretrato, com a produção de acrósticos e de autobiografias. "Nesses textos, os alunos iam contando suas preferências, seus medos, sonhos e esperanças", disse a professora Carol.

Ainda de acordo com Carol, na proposta de trabalho Matemática e Minha Identidade, os alunos "puderam trabalhar com a linguagem gráfica a partir de peso e altura, mês, ano e hora de nascimento e, a partir daí, construíram conhecimentos matemáticos sobre os Estados de origem, ano de nascimento, altura e mês de aniversário".

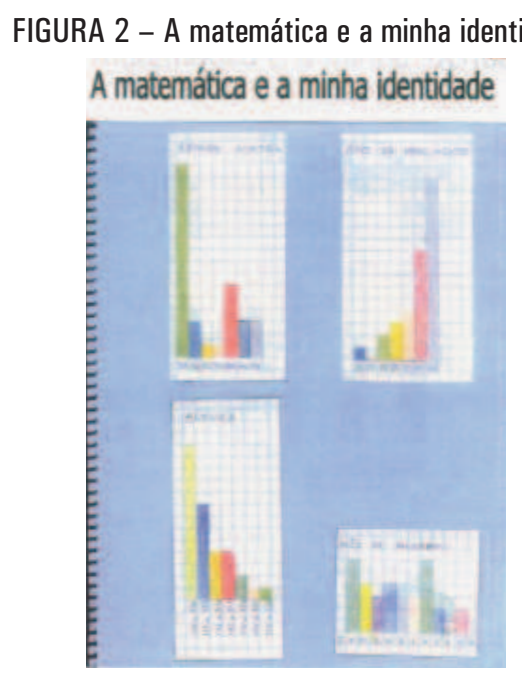

Fonte: Arquivo pessoal da professora Carol 
Como o grupo vinha de diferentes lugares do país, a partir de sua procedência, começaram a estudar geografia por meio da localização de mapas. Assim, integrando as áreas de conhecimento, os alunos foram coletando dados, trabalhando novas ideias e conceitos, sempre por meio de suas histórias de vida: trabalhos com o nome, alfabetização, autoestima, entre outros.

Esses dados serviram de ponto de partida para a elaboração do planejamento, pois, conhecendo melhor as crianças e suas necessidades, os professores poderiam estabelecer os objetivos pretendidos. As professoras relatam que buscavam conhecer os educandos, criar situações, suscitar problemas úteis, que levassem à reflexão, à busca do autoconhecimento, para que pudessem construir-se e assim construírem uma sociedade mais cidadã.

Assim, com os dados obtidos a partir do "eu", os alunos passariam ao conhecimento do "nós", e foram em busca de conhecer o bairro, a comunidade, a cidade e, também, os outros, aqueles mais distantes de sua realidade local. Era o momento de compreender as dificuldades que surgiram no cotidiano e, na tentativa de saná-las, as professoras propuseram aos alunos uma pesquisa de campo, nos bairros onde eles residiam, com o objetivo de ampliar o olhar dos estudantes em relação à comunidade, numa atitude de investigação e de busca de soluções para os problemas pesquisados.

Para isso, os professores pensaram nas ações que deveriam tomar: verificaram os meios de que dispunham e quais outros precisavam criar. Não poderiam contar com a escola no que se referia a verba para viabilizar as atividades extraclasse, provavelmente nem com as famílias. A verba para as atividades veio de bazares beneficentes e de um bingo, ambos organizados pelos professores.

A professora Vanessa sempre ressaltava a importância da participação da comunidade nas lutas da escola, como no caso do movimento para substituição das salas de aula de madeirite por salas de alvenaria. Ainda de acordo com a professora, "a direção tinha a intenção de trazer a comunidade para participar da parte pedagógica, mas os pais ainda não estavam prontos para essa participação, pois primeiro tinham que se aproximar da escola". E complementa esclarecendo que o conflito em torno das vagas para os novos alunos, de um problema de ordem estrutural e física, acabou propiciando a aproximação dos pais e sua participação ativa no trabalho pedagógico da escola. 
Nessa nova etapa da pesquisa, segundo a professora Vanessa, as seis classes de $3^{a}$ série fizeram um levantamento preliminar dos bairros próximos à escola. $\mathrm{Na}$ medida em que os alunos começaram a trazer algumas informações que coletavam com os pais em casa, foi sendo elaborado um roteiro, e elas foram a campo. Em seguida, cada grupo escolheu o espaço a ser investigado, cada duas professoras visitaram dois bairros diferentes, todas as seis salas de $3^{\text {as }}$ séries, ao mesmo tempo, de mochila nas costas, saíram a pé, com prancheta na mão, cantando a música "Se essa rua fosse minha". Assim, os alunos foram observando tudo: tipos de moradia, pontos comerciais e industriais, condições de saneamento básico, transporte, sinalização, preservação do meio ambiente, fizeram entrevistas com pessoas que estavam indo embora do bairro, anotaram as reivindicações, entre outros aspectos. "Os alunos puderam mostrar onde moravam, visitaram a casa de um colega da classe, passaram informações que tinham sobre o local, colheram outras informações nas entrevistas com moradores, comerciantes e lideranças de bairro", disse a professora Vanessa.

\section{FIGURA 3 - Visita aos bairros legalizados e não legalizados}

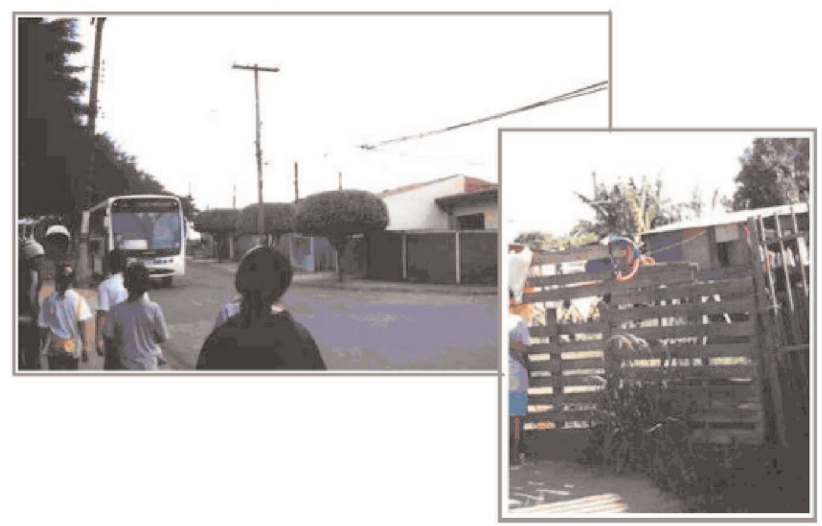

Fonte: Arquivo pessoal da professora Susana

Ela informa ainda que, quando os alunos voltavam para a sala de aula, faziam o relatório do que foi visto, do que haviam observado, das entrevistas que haviam sido feitas com funcionários antigos do bairro, com a líder da comunidade e os demais depoimentos. Um exemplo desse trabalho pode ser observado a seguir, na tabela sobre as condições de 
moradia dos estudantes, resultado do trabalho dos alunos, incorporado ao Projeto Pedagógico da escola:

Tabela 1 - Condições de moradia dos alunos do período vespertino

\begin{tabular}{c|c} 
CARACTERÍSTICA & OCORRÊNCIA \\
\hline Água encanada & $92 \%$ \\
Energia elétrica & $93 \%$ \\
Coleta de lixo & $91,7 \%$ \\
Iluminação pública & $86,1 \%$ \\
Transporte coletivo & $76,9 \%$ \\
Rede de esgoto & $60,2 \%$ \\
Asfalto & $51,9 \%$ \\
Computador & $31,5 \%$
\end{tabular}

Fonte: Projeto Político Pedagógico 2008/2009

Os dados coletados eram utilizados para a construção de conhecimentos de Matemática, Língua Portuguesa, Ciências, História e Geografia e eram produzidos simultaneamente por meio de textos, da revelação de fotos tiradas durante as pesquisas, de escritas individuais e em grupo.

De acordo com as professoras, para as crianças, o estudo do meio teve muito valor. Houve várias discussões que envolveram assuntos como a falta de lazer no bairro, o porquê do número de igrejas estar aumentando, a violência que levava as pessoas a abandonarem o bairro, o que acabava diminuindo o comércio. Perceberam, também, a omissão do poder público em alguns casos e, em outros, a preocupação em proporcionar melhores condições de vida para a população.

A partir desse trabalho, os alunos observaram que os bairros próximos da escola, mesmo nas partes mais antigas, não estavam tão bemestruturados quanto poderiam, o que as levou a concluir que somente com a união dos moradores dos bairros é que muitos problemas seriam solucionados.

"A partir desses estudos, o grupo foi se conhecendo, respeitando o modo de vida de cada um e as pesquisas foram acontecendo sobre doenças, dengue, verme, piolho, procurando desenvolver a responsabilidade com o próprio corpo e com os espaços que habitam", disse a professora Vanessa.

Esses materiais produzidos pelos alunos foram divulgados em exposições para os próprios colegas. Vanessa disse que: "com essas ativi- 
dades, estávamos oferecendo aos alunos oportunidades para uma aprendizagem mais significativa e dotada de finalidade".

A respeito desse trabalho na escola, a professora Carol enfatizou a necessidade de trabalhar os conteúdos contextualizados com a realidade e que essa realidade norteasse os conteúdos trabalhados. Nessa perspectiva, afirmou que foram "desenvolvendo um trabalho de socialização das informações entre as classes e isso possibilitou uma aprendizagem mais contextualizada e garantiu um novo espaço de interação e respeito às diferenças sociais".

Em seu depoimento, a professora Vanessa diz que: "Sem dúvi$\mathrm{da}$, esse projeto foi um dos pontos mais positivos porque serviu de ponto de partida para criarmos um vínculo com as crianças e com os pais, porque percebíamos que não adiantava trabalhar somente com os alunos". A respeito dos resultados dos trabalhos de campo, Vanessa salienta que:

No desenvolvimento da pesquisa, os alunos passaram a sentir a importância do relato oral e escrito, com coerência e coesão, pois, na volta à sala de aula, os alunos elaboravam os relatórios sobre o que era visto por eles e, assim, ampliavam a compreensão do processo de funcionalidade da escrita. Também os conceitos matemáticos tornavam-se mais significativos ao serem relacionados com situações-problemas, vivenciados a partir dos estudos de campo, e os vínculos de amizade começaram a aparecer entre eles, minimizando, assim, os conflitos.

Ainda nesse sentido, a professora Carol relata que, em muitos desses momentos, tiveram a presença de funcionárias da escola que ainda moravam nesses bairros e conheciam bem suas histórias e puderam contá-las aos alunos. Ressalta ainda que: "Foi muito importante esse encontro dos moradores antigos com os alunos, além de momentos agradáveis, os alunos perceberam o quanto eles tinham a ensinar". Sobre o que foi feito a seguir, a professora Vanessa relatou que:

Depois de registradas a história de vida de cada um, da família, do entorno da escola e as possibilidades de intervenção no meio, mostrar a importância das relações humanas para o conhecimento, foram ampliado para um universo maior: discutiram a questão da migração e suas causas, segundo a história de vida de cada família. Vantagens e desvantagens da zona rural e urbana, os tipos de trabalho na região metropolitana de Campinas e, a partir daí, entraram nas questões que envolvem o trabalho, a escravidão, a exploração do tra- 
balho infantil, do preconceito para com a mulher, o idoso, respeito às diferenças. Sempre integrado as áreas de conhecimento.

Para expandir os horizontes dos estudos, as crianças foram conhecer a rodoviária, a ferroviária e o aeroporto. O objetivo não era apenas fazer um passeio pela cidade, mas as professoras queriam que os alunos relacionassem as histórias da vinda das famílias para Campinas com os conteúdos trabalhados, como, por exemplo, os meios de transporte. Para surpresa de todos, foram os professores que mais aprenderam com esse estudo do meio, disse a professora. Nesse sentido, destaca-se, em especial, a ida à ferroviária, pois os bairros próximos da escola eram cercados por linhas de trem, sendo que os alunos tinham muito conhecimento das manobras ali realizadas. Em relação à visita à rodoviária, a professora revela que:

Fica difícil descrever como os alunos se entusiasmaram. Primeiro porque foram muito bem-recebidos na rodoviária e principalmente porque o centro de interesse deles era muito grande. Foram pesquisar em quais guichês deveriam comprar a passagem, por quais empresas, compararam preços, entrevistaram funcionários, observaram o comércio interno e o tipo de prestação de serviço que a rodoviária oferece aos seus usuários.

De acordo com as professoras entrevistadas, nada motivava os alunos no aeroporto, a indiferença era tanta que até a postura dos alunos mudou. O único momento de que os alunos gostaram foi quando um dos funcionários fez sumirem, "misteriosamente", as mochilas na esteira de malas. Uma exceção, porque a maioria dos funcionários e passageiros ignorava as crianças e se negava a responder à pesquisa dos alunos.

Nesse caso, as professoras perceberam que os alunos rejeitavam e desvalorizavam as coisas que não faziam parte de sua cultura. Ainda assim, os professores acreditavam que é função da escola garantir que tenham acesso a todo tipo de conhecimento e, por meio desses passeios, puderam analisar e comparar as diferenças entre os meios de transporte e trazer sentido para os conteúdos matemáticos, como medida de tempo, de distância, concepção de lucro e prejuízos.

Ainda de acordo com as professoras, esses estudos despertaram outras pesquisas, outras visitas, que permitiram a tomada de consciência do papel de cada um na preservação do ecossistema, gerando uma nova proposta de trabalho sobre lixo e reciclagem, o que despertou interesse, 
por ser a coleta de material reciclável a forma de sobrevivência de alguns moradores do bairro.

"No coletivo, fomos buscando a unidade escolar, garantindo espaços para o diálogo, socialização e busca de soluções para as dificuldades e diferenças que surgiram no cotidiano. Entre erros e acertos fomos construindo nossas práticas pedagógicas", comentou a professora Vanessa. E complementou:

Durante quatro anos, inúmeras atividades foram construídas, atividades que estiveram presentes nas exposições escolares, em cada gesto, em cada professora, em cada família e sobremodo, em cada criança que as vivenciou. Cada casa guarda, certamente, com imenso carinho, um pedaço do que pudemos construir naquela época.

\section{Considerações finais}

No intuito de ser coerentes com o propósito político de ajudar a educação a avançar por trilhas transformadoras da realidade, ainda que conscientes de suas tantas limitações, buscamos retratar, neste trabalho, ideias e práticas que podem contribuir com a educação, melhor dizendo, para uma educação emancipadora dos homens e crítica da realidade.

Após constatar alguns equívocos quanto à ideia de pesquisa na educação básica, encontramos um grupo de professores que, movido pelas demandas locais e pela necessidade de tornar o pedagógico mais político e o político mais pedagógico, lançou mão da pesquisa como princípio educativo.

Apesar de não termos uma resposta específica das professoras dizendo qual o seu conceito de pesquisa, as atividades que vêm realizando em sua prática cotidiana nos permitem depreender que a entendem de modo próximo ao sentido por nós buscado de pesquisa como princípio educativo. Essas professoras se desafiaram e desafiaram os alunos, então na terceira série do ensino fundamental, para transformar o cotidiano em objeto de investigação, estimulando-os ao questionamento, ao levantamento de hipóteses, em uma abordagem crítica e contextualizada.

Embora não tenhamos depoimentos de alunos do período, uma vez que já haviam deixado a escola no momento de realização desta pesquisa, os resultados do trabalho desenvolvido com eles transpareciam na 
fala das professoras, bem como no conjunto de textos realizados pelos alunos.

É importante mencionar que a cultura de trabalho pela pesquisa, originada no momento da necessidade, foi, posteriormente, o embrião de uma parceria com a Unicamp (Universidade Estadual de Campinas) para o desenvolvimento do projeto Ciência na Escola - primeiros passos. $\mathrm{Na}$ atualidade, a professora Vanessa mantém o ideal do questionamento reconstrutivo numa atividade que denominou de "tribuna". Nesse espaço, os alunos podem trazer, a qualquer momento, dúvidas, questionamentos, reclamações sobre assuntos cotidianos que os afligem e, mediante organização da sala, as temáticas são discutidas. Em caso de necessidade, realiza-se uma investigação e respostas, alternativas ou simplesmente pontos de vista, são compartilhados. A nosso ver, esse é um indício de que a prática da professora Vanessa continua abrindo espaço às explorações, aos sentidos que os alunos estabelecem em relação ao mundo, à vida, às relações humanas, ao que estão estudando.

Ao longo da presente pesquisa, pudemos observar, também, que a infraestrutura, embora muito importante, não foi elemento imobilizador para o trabalho de professores e alunos. Ao contrário, levou a comunidade a uma mobilização na busca de recursos, por meio da organização de bazares, por exemplo, para financiar as visitas à rodoviária e ao aeroporto, bem como para reivindicar melhores condições para as salas de aula. Essa experiência nos permite, ainda, ressaltar o caráter político da prática pedagógica e o compromisso docente com as classes menos favorecidas, destacando a importância do professor como sujeito na transformação da realidade social de seus alunos, valorizando a discussão sobre a função da escola sob uma perspectiva social mais global.

A diversidade socioeconômica e cultural da comunidade escolar refletiu no trabalho pedagógico da escola, e exigiu dos profissionais comprometimento político e pedagógico, percepção dos pontos problemáticos nas discussões das contradições existentes, trabalho coletivo, que repensasse valores e procedimentos, para que a escola fosse verdadeiramente democrática e competente na sua função, espaço de transformação, aproximando-se das ideias defendidas por Giroux, anteriormente expostas.

$\mathrm{Na}$ busca de soluções para os problemas de aprendizagem de alunos com grande defasagem de conteúdos propostos para a série em que se encontravam, para os conflitos sociais e para os problemas estru- 
turais da escola, os professores foram despertados para o valor da pesquisa como recurso de ensino e aprendizagem. Mais que isso, os professores, por meio do trabalho coletivo, foram construindo, garimpando instrumentos para o exercício de uma atividade criativa e crítica, com questionamentos e a indicação de soluções, abrindo frentes, em "sintonia" com a comunidade. Dessa forma, o trabalho no dia a dia possibilitou minimizar os conflitos e ir ao encontro de novas possibilidades de convivência e reconstrução do conhecimento produzido e sistematizado pela humanidade.

Os resultados dessa experiência, que consideramos emblemática, apontam que é possível desenvolver na escola básica uma prática pedagógica que articule ensino e pesquisa, tornando esta última uma fonte catalisadora de desenvolvimento integral e intelectual dos alunos, bem como de integração entre escola e comunidade. 


\section{Referências bibliográficas}

ANDRÉ, M. (Org.) O papel da pesquisa na formação e na prática dos professores. Campinas: Papirus, 2001. p. 55-69.

BAGNO, M. Pesquisa na escola: o que é, como se faz. São Paulo: Loyola, 1998.

DEMO, P. Educar pela pesquisa. Campinas, SP: Autores Associados, 1997.

DEMO, P. Pesquisa: princípio científico e educativo. São Paulo: Cortez, 1992.

ELLIOT, J. Educational theory and the professional learning of teachers: an overview. Cambridge Journal of Education, v. 19, n. 1, p. 81-100, 1989.

FREIRE, P. Pedagogia da autonomia: saberes necessários à prática educativa. São Paulo: Paz e Terra, 1999.

FREIRE, P. Educação como prática de liberdade. Rio de Janeiro: Paz e Terra, 1989.

FREIRE, P. Educação e mudança. Rio de Janeiro: Paz e Terra, 1979.

FREIRE, P.; FAUNDEZ, A. Por uma pedagogia da pergunta. Rio de Janeiro: Paz e Terra, 1985.

FREIRE, P. Conscientização: teoria e prática da libertação: uma introdução ao pensamento de Paulo Freire. São Paulo: Moraes, 1980.

GARCIA, M. F. A produção do conbecimento na escola pública por meio da pesquisa: o projeto "ciência na escola". Tese (Doutorado em Educação). UNICAMP. Campinas, 2002.

GIL, A. C. Como elaborar projetos de pesquisa. 4 ed. São Paulo: Atlas, 2002.

GIROUX, H. A. Os professores como intelectuais: rumo a uma pedagogia crítica da aprendizagem. Porto Alegre: Artes Médicas, 1997.

LÜDKE, M. O professor e a pesquisa. Campinas, São Paulo: Papirus, 2001a.

LÜDKE, M. O professor, seu saber e sua pesquisa. Educação e Sociedade. Campinas, n. 74, p. 77-96, 2001b.

LÜDKE, M; CRUZ, Giseli B. da. Aproximando universidade e escola de educação básica pela pesquisa. Cadernos de Pesquisa, v. 35, n. 125, 2005.

MARAFON, M. R. C. Pedagogia crítica: uma metodologia na construção do conhecimento. Petrópolis, RJ: Vozes, 2001.

MELLO, G. N. Magistério de $1^{\circ}$ GRAU: da competência técnica ao compromisso político. São Paulo: Autores Associados, 1982.

MINAYO, M. C. S. (Org.). Pesquisa social: teoria, método e criatividade. 22 ed. Petrópolis, RJ: Vozes, 1994.

NARDI, R.; BASTOS, F.; DINIZ, R. E. S. (Org.) Pesquisas em ensino de ciências: contribuições para formação de professores. São Paulo: Escrituras Editora, 2004.

SAVIANI, D. Escola e democracia. Campinas, SP: Autores Associados, 2003. (Coleção Polêmicas do Nosso Tempo).

SAVIANI, D. Pedagogia histórico-crítica. Campinas, SP: Autores Associados, 2000.

SHÖN, D. Formar professores como profissionais reflexivos. In: NÓVOA, A. (Org.) Os Professores e sua formação. Lisboa: Dom Quixote, 1992.

STENHOUSE, L. An introduction to curriculum research and development. Londres: Heinemann, 1975.

ZEICHNER, K. Refletindo com Zeichner: Um encontro orientado por preocupações políticas teóricas e epistemológicas. In: GERALDI, C.M.G.; FIORENTINI, D.; PEREIRA, E.M. de A. (Org.) Cartografias do trabalho docente: professor(a)-pesquisador(a). Campinas: Mercado das Letras/ ALB, 1998. 
Endereço para correspondência: Pontifícia Universidade Católica de Campinas

Rodovia D. Pedro I, km 136

Parque das Universidades

Campinas - SP

13086-900

Data de recebimento: 04/03/2009

Data de aprovação: 10/11/2009

Educação em Revista | Belo Horizonte | v.26 | n.02 | p.249-276 | ago. 2010 